\title{
Database System Development for the Care of Elders in the Community
}

\author{
Urai JARAEPRAPAL ${ }^{1}$ and Puangrat JINPON ${ }^{2, *}$ \\ ${ }^{1}$ School of Nursing, Walailak University, Nakhon Si Thammarat 80161, Thailand \\ ${ }^{2}$ Information Technology and Educational Media Center, Southern College of Technology, \\ Nakhon Si Thammarat 80110, Thailand
}

('Corresponding author's e-mail: jpuangrat@gmail.com)

Received: 31 May 2017, Revised: 17 July 2018, Accepted: 20 August 2018

\begin{abstract}
This participatory action research aimed to develop a database system for the care of elders in the community, Pak Poon sub-district, Nakhon Si Thammarat, Thailand. The key informants were composed of public health officers, community leaders, representatives of the Local Administrative Organization, elders and their families, and lecturers and nursing students of Walailak University. Research instruments included interview questions, an elderly health assessment form, a developed elderly health database system as an experimental tool, and a usability evaluation form. Data collection was conducted by survey, interview, group discussion, and observation. Quantitative data analysis was conducted by frequency distribution and percentage; the validity and reliability of the questionnaire were confirmed with experts for Cronbach's alpha. The qualitative data revealed content analysis. The results show that the database system consists of, elder health assessment, comprising general information, prior illness and treatment, functionality, mental health risk, risk for fall, and environment, the required features to support achievement of the goal for well-being, consistent with their life style, social capital, and local wisdom. In addition, the database could be used to reduce early risk factors to protect from chronic illness, injury, and decline in physical and psychosocial function. The reporting requirement comprised frequency distribution in terms of capital, problems, and need. Perception of the system and its effectiveness were evaluated using a questionnaire after participants had had an approximately one month period of experience of using the system. The responses to the questionnaire were positive about the system features and system process. From executives and health officers and elders using the database system, it has been improved, based on feedback continuum.
\end{abstract}

Keywords: Clinical decision support, older adult, database health system, data visualization, clinical informatics

\section{Introduction}

The global trend of elders is on the rise, increasing from $10 \%$ in 2000 to $15 \%$ in 2025 . In Thailand, the number of elderly, which had remained steady at 9.4 percent in 2000 , drastically grew to $20 \%$ in 2025 [1], indicating the arrival of an elderly society in $2024-2025$ [2,3]. Old people affect society in two aspects: 1) As a benefit to society, due to their ideal role in giving advice to younger generations, taking care of grandchildren in the family, and passing on empirical knowledge to both interested individuals and society, etc.; 2) Old age naturally comes with increased dependency on society. Deteriorated bodies could possibly cause health problems, or even disabilities. As a result, financially and socially relying on others for basic needs is common. It was estimated that the number of the elderly unable to help themselves would increase from 94,200 in 2010 to 739,600 in 2040 [4]. The government has had to allocate healthcare management service budget to elderly care at a proportion of 2.5 times more than that given to those of working age [5]. Therefore, the government stressed the importance of the elderly care 
http://wjst.wu.ac.th

system by the community [6,7], because those close to the elderly can best provide relevant care to them and help cut down some unnecessary service costs as well $[8,9]$.

From community phenomena and literary reviews, it has also been found that both health and social services for the elderly are not universally available. The main cause for this is that older people have difficulty accessing the service, due to limited travel to the service unit being available. Therefore, improving proactive health care services is a challenge for caregivers [10]. The factor that causes a health teams to be unable to provide health services is the lack of systematic information about the elderly, such as information of the elders' potential, problems, and needs [3]. There are no specific data sets on the elderly, therefore, no information to use to communicate with associated care with other relevant organizations, for example, to use for sub-district level planning development for the care of elders. Most care is available at hospitals, such as health screening and caring for chronic illnesses, and there is a lack of proactive activity to empower older people in the community. As a result, the elderly waste time and lack the opportunity to receive a variety of care.

Currently, there is a growing use of elderly care databases [6,8], as a result of: enabling the elderly to receive effective care, such as using information to design health care and support older people to access health information and use it for their self-care [6]; helping vulnerable frail older adults get more effective care [8], and helping older adults with dementia receive effective care [11]. Increased service system efficiency, due to the use of contextual information to solve differential problems of the elderly [12], presents outcome evaluation for policy making to decrease budget planning, and it can be used as a tool for coordination between health care teams and other related organizations in charge of the care of elders. This situation allows the Bureau of Promotion and Protection of the Elderly to set a policy so that elderly care workers in the community should develop an elderly database for continuing care: planning, implementation, and monitoring of elderly care for efficient improvement of elder care results [13].

Although database systems are recognized as an important tool in increasing service quality, and continue to develop, existing knowledge is still limited for elder care, as there are no data sets or specific databases available yet for elderly care planning; the elderly differs from other age groups in taking care of them physically, mentally, socially, and intellectually, and there are no data available for using elderly health promotion planning to slow down aging and to have a long life with quality, Finally, most knowledge is in the field of information, but this area occurs in the profession of nursing, which is a specialty; other occupations fail to understand the nursing, leading to the analysis of information systems that have non-responsive databases to support professional work in the nursing process.

The School of Nursing, Walailak University, is a nursing institution that plays a major role in producing new knowledge to serve society and to raise awareness of these problems; this participatory action research was used to study the "Database System Development Supporting Older Adults Care". This study aimed to developed a database health system for older adult care in community; the information from the database supporting policy decision would allow health care teams and related organizations to organize caring consistent with the context of elders, such as planning, implementation, monitoring, and evaluation, and to study the results of using a developed database system and improving it to meet the needs of users.

The results of this study will support health teams in data storage, and can be used to develop a service that can improve elder health status in the community, focus on health promotion and the prevention of early health problems and illnesses caused by aging and chronic diseases, slow down aging in physical and psychosocial functioning for the goal of maintaining health status, and allow elders to live a long life with full potential and a healthy balance in accordance with the way of life in a family context society and local culture. 


\section{Materials and methods}

\section{Participants and sampling}

This research studied the population living in Pak Poon sub-district, Muang, Nakhon Si Thammarat, Thailand. The key informants of this study consisted of health teams involved in health care for the elderly and the elderly and their families, as follows: 1) research teams were 5 nursing instructors and 43 nursing students from the School of Nursing of Walailak University; 2) Those involved in the provision of elderly services in the community included: 2.1) 4 persons of the management team of Pak Poon Subdistrict Administration Organization, consisting of the prime minister and the deputy, the head of the Health and Environment Division, and the Director of Bangpu Health Promotion Hospital, 2.2) 3 health and nursing staff of the Elderly Care and Services Division of the Pak Poon Public Health Service, 2.3) 5 caregivers from the public sector, including elder care volunteers, and volunteer caregivers for the disabled, 3) 908 elderly people, the size determined by the Yamane schedule, with a comparable population of 3,482 elderly people in the district, and obtaining 843 elderly people (95\% confidence interval, $3 \%$ random variation), and proportional stratified random sampling done by determining the size of the elderly population of each village to the total number of elderly people present.

\section{Research methods}

This study adopted participatory action research (PAR) as its main methodology, because it studied the need for data sets and a database system that supported health care teams using these for the care of elders in community. It was developed based on the needs of the users and to be tested and developed to meet their needs. PAR approaches have been demonstrated to be a helpful tool to provide a process for health care teams in the community to come together to address their own needs for datasets and database systems for development [14]. A 4-step action research cycle was used with the Kemmis and McTaggart framework [15]: Planning, Action, Observation and Reflection, in 3 phases of research: phase 1, development of study design and data collection; phase 2, development and implementation of the database system for care of elders in the community, and phase 3, evaluation of the database system and the end of the research.

\section{Phase 1- development of study design and data collection}

This phase was composed of 4 steps: 1) the research team was established from university researchers and community based research teams who were involved with caring for the elderly in the community; 2) the study purpose and the benefits expected were explained to them; 3) the research team who worked in the academic area was trained on community storage skills for data collection assistants, and 4) the need of data sets and a database system for elderly care from all sectors was studied, preparing the data into the database development cycle in the next period (February 2011 - May 2011).

\section{the community \\ Phase 2- development and implementation of the database system for the care of elders in}

Researchers observed the health team activities in developing database systems and reflecting on the activity information for those involved in the process of developing, improving, and planning new operations. This phase composed of 6 steps: 1) database initial study- studying the database need from all related sectors to define the aims, problems, scope, and rules of the database system to be developed; 2) database design from data gathering in the first step; 3) implementation and loading- creating the database for entering the actual data; 4) testing and evaluation- testing the database system by the health teams to trial, give suggestion, find various errors, and evaluate capabilities to use as guidelines to improve the database system to meet the needs of users properly; 5) operation of the database system after being developed successfully, and 6) maintenance and evaluation- this process occurring during using of the actual database system, then modifying in case of addition, or changing the needs of the user which affects the database system, with maintenance for effective operation (July 2011 - March 2014). 


\section{Phase 3- evaluation of database system and end of research}

This phase was the summary of the database development process; the researchers and health teams attended a conference for final evaluation in order to learn about the whole process, to find conclusion factors that made the development successful, and the factors that hindered the development, to proposed the findings to make public policy, and to reflect the results of the research given to the community (April 2014 - September 2014).

\section{Research tools}

Quantitative and qualitative tools were used in this research. The quantitative tools were composed of two questionnaires, an elderly health assessment and a usability evaluation assessment. The content and constructive validity of the questionnaires were confirmed with 3 experts in public health for the elderly health assessment and 3 experts in database management for the usability evaluation assessment. Internal consistency was tested using Cronbach's alpha to evaluate the degree of measurement error within each subscale. Acceptable values were greater than 0.700 . The reliability of the questionnaires was confirmed, with Cronbach's alpha of 0.87 for the elderly health assessment and 0.85 for the usability evaluation assessment.

The qualitative tool and trustworthiness building proceeded as follows: 1) before the study started, 5 researchers and research volunteers developed their potential by educating themselves in and practicing research skills; 2) semi-structured questionnaires for interview and group discussion, concerning the health care team needs for data sets and a database system for caring for the elderly, were developed and confirmed by the brainstorming of 5 experts after trying them out and adapting them to suit the area, and 3 ) data triangulation in the health care teams and the elders were confirmed with recording, trial, and improving valid data by the observations of the health care team behavior in the process of data set and database system development.

The database system was used as an experimental tool to support the health teams in the care of elders in the community.

\section{Data collection}

This study collected data by group discussion, brainstorming, in-depth interview, and observation in the study process at every step, recorded in field note forms and the elderly health survey in Pak Poon sub-district.

\section{Database system architecture}

The database system has been developed using web-based technology, Business Intelligence (BI) concepts, and open source computing environments [16-18], that is, MySQL, PHP, Highcharts JS, and Google Maps. The Apache web server 2.2.8 and MySQL 5.0.51b are used as web server software and a database management system, respectively. Highcharts JS is used to develop visualization and data analysis tools, which displays a diversity of charts on web pages [19-21]. Highcharts JS adds interactive calculations and impressive visualizations to websites by integrating objects embedded with PHP scripts and HTML tags (37). Google Maps is used to visualize interesting factors and to plan routes [22].

\section{Database system development process}

According to a database life cycle (DBLC) [23], the participant observation between the researchers and the health teams was used in this study. These sets of processes were used to reflect the activity information, improve the processes, and revise the plan to accomplish the purpose. DBLC involved six steps: database initial study, database design, implementation and loading, operation, testing and evaluation, and maintenance and evaluation, which can be described as follows:

1. Database initial study: this step was used to collect and analyze the system requirements from the health team and users of the system, to support decision making to plan and evaluate the older adult care. Two results were obtained in this step: the objective of the system use and the system report. Two objectives were determined from the health teams in utilizing information: first, this information was used to enhance elder happiness based on their lifestyles, health and social resources, and the local wisdom of 
http://wjst.wu.ac.th

elders in the community. After implementing the activities, the initial risk factors were reduced because of health prevention, such as chronic diseases, injuries, and deterioration in physical and psychosocial functioning in elders. Four reports were required: 1) a report in easy-to-understand format, such as a graph and on-page comparison; 2) a personal information frequency report, such as religion, education, caregiver, and health history; 3) diseases found in elders ordered by disease and community, and 4) the distribution of diseases found, plotted in Google Maps and point travel detail.

2. Database design: data requirements from the first step were utilized to determine the design of the database, and then using database creation and design tools to communicate between the designers and programmers, such as ER diagrams and data dictionaries.

3. Implementation and loading: the database system was produced and the data was input into the database system. The system performance, security, and standard setup were evaluated by users.

4. Operation: the database system was used by the health teams as follows: 1) questionnaires with the geographic coordinate (GPS) of houses were collected; 2) the data from questionnaires with the geographic coordinate (GPS) of houses were input into the system, and 3) the system generated reports for appropriate planning in individual contexts.

5. Testing and evaluation: the effectiveness and user perceptions of the system were evaluated by the health teams. Their comments were used to enhance the performance of the system to meet the user needs in various fields correctly and completely. An end user manual was developed to guide users in system use.

6. Maintenance and evaluation: while using the database system, it was analyzed and some functions or processes changed to be more efficient, because of changes in the requirements, or in the implementation environment, by bug fixing or porting of the system to new environments.

\section{Statistical analysis}

Automatic calculation tools were developed using statistical analysis concepts, such as frequency distribution and percentages (\%) for nominal data. Ordinal data were described with mean values and standard deviations (SD) using SPSS. The qualitative data used content analysis along with the data collection process, and post-retrospective data analysis to generate conclusions from the research.

\section{Usability evaluation}

The effectiveness and user perceptions of the database system were evaluated through use of 16 questionnaires under four main headings: user-program interaction, database system features, system performance and security, and satisfaction with the service quality of the system. We selected 57 users, covering all user groups. The selected user groups were made up of one health center's staff members, 2 management teams of Pak Poon Sub-district Administration Organization, 8 health care volunteers, and 3 nursing lecturers and 43 nursing students of Walailak University. Designated lecturers and nursing students had been using the database system for one month prior to the evaluation process in the course of their duties and data were collected and input onto the system. For health center staff members, management teams, and health care volunteers, we organized meetings, demonstrated the database system, and allowed them to use it for one hour prior to the evaluation process in the course of their duties with a view to decision making. The participants were given a questionnaire during the meetings; they were asked to fill out the questionnaire, indicating their level of agreement with the statements, using a five-point Likert scale. The participants' anonymous responses were collected. As experiences in using the systems were different, we separated the analyzed the results into two parts: manipulated data users and those with a view to decision making.

\section{Ethics statement}

This study was approved by the Ethical Clearance Committee on Human Rights Related to Researches Involving Human Subjects, Walailak University (Number 51/034: 25/11/2008). 
http://wjst.wu.ac.th

\section{Results and discussion}

\section{System description}

The system was designed to be used by three user groups: 1) system administrators, actioned as managed users and those who solved incorrect data entry by users; 2) data entry users, actioned as inputting data into the system, and 3) general users, actioned as reporting all data based on their privileges. Users could access the database system by logging into the system, though users who did not $\log$ in did not have access to any information or reports. For security reasons, the login system required a username and password, only obtainable from the system administrator. The Facebook page, FAP aging at URL: https://www.facebook.com/fapaging, was used to coordinate, advise, and solve problems for users. Since March 2014, a prototype database system has been available online at URL: http://fapaging.welfarepakpoon.org (Figure 1). At present, the database system contains data from 908 older adults, in twelve communities. Following the login, the user could choose two main functions: older adult data entry and user management.

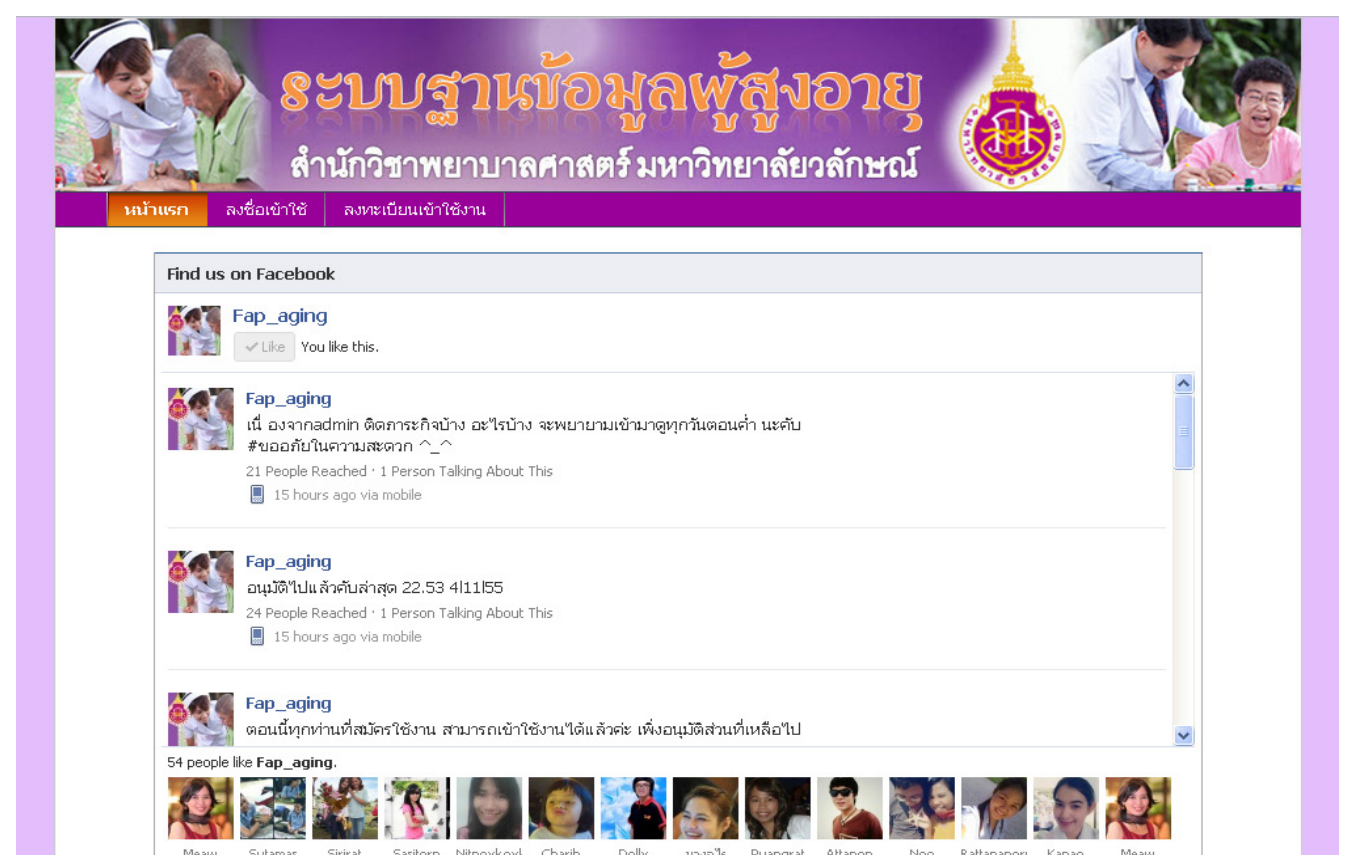

Figure 1 Home page of the database system providing access method and user listed in Facebook account with their thumbnail profile picture.

\section{Data entry}

The data entry requirement for decision making to take care of elders was composed of two parts: elders and caregiver information. The elder information consisted of eight items: 1) personal information, such as name and surname, gender, age, address, ID card number, marital status, educational, and caregiver; 2) past history, such as surgery history and health check-up; 3) drug history; 4) physical examination; 5) functional assessment, such as the Barthel ADL and the Chula ADL index assessment; 6) risk assessment and common problems, such as quality of life and happiness, risk factor for falls and fear of falls, excretion, and malnutrition; 7) cognitive assessment, such as the Chula mental test (CMT) and Thai geriatric depression scale (TGDS), and 8) environmental assessment at home. The caregiver information consisted of caregiver type, relationship with the elder, and caregiver personal information, such as education and income. In summary, the data entry of the database system was composed of four 
http://wjst.wu.ac.th

parts: users and privileges, questionnaires, data from questionnaires, and reports for decision making support in care taking.

(a)

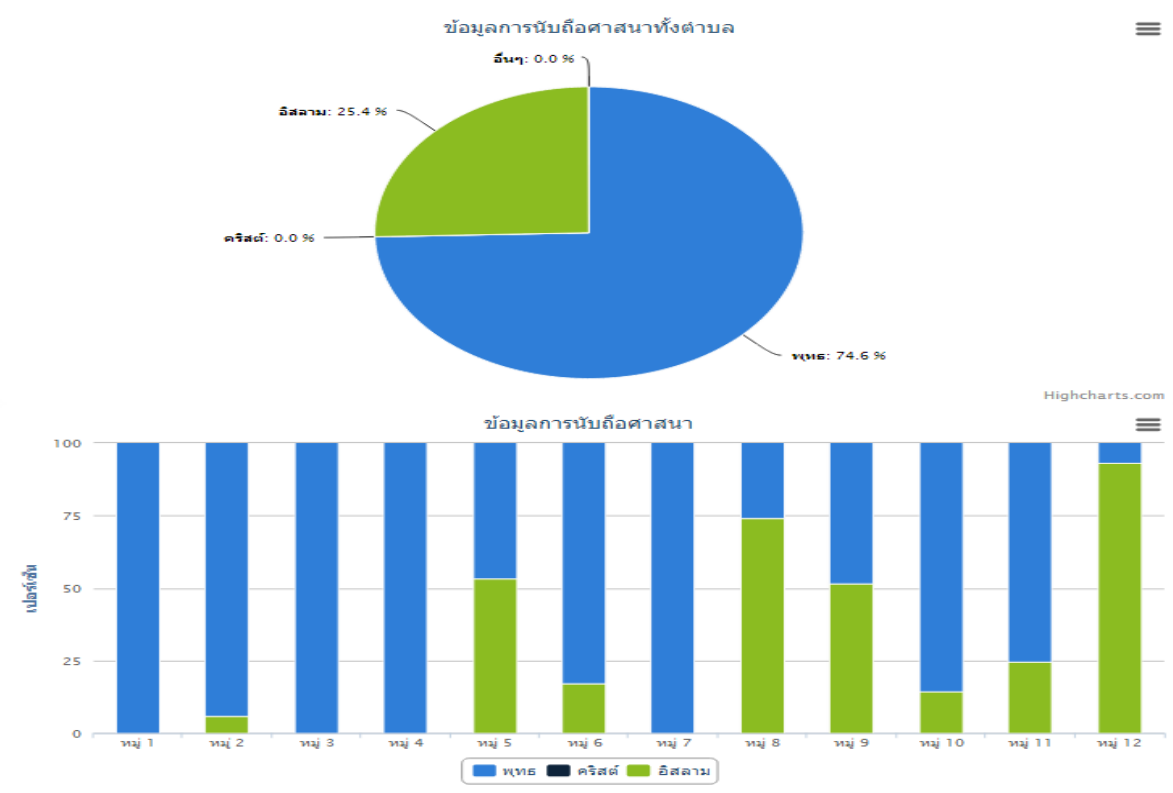

(b)

\begin{tabular}{|c|c|c|c|c|c|c|c|}
\hline หมู่ & $\begin{array}{l}\text { โรคหลลอดเลือดห้วใจ } \\
\text { พัวใจขาดเลือด กล้าม } \\
\text { เนื้อหัวใจตาย }\end{array}$ & $\begin{array}{l}\text { โรคหัวใจอี่น ๆ } \\
\text { พัวใจวาย ลื้น } \\
\text { พัวใจรั้ว }\end{array}$ & $\begin{array}{c}\text { ตวาม } \\
\text { ตัน } \\
\text { โลนิต }\end{array}$ & $\begin{array}{l}\text { โรค } \\
\text { นิด } \\
2\end{array}$ & $\begin{array}{l}\text { โรดปอด } \\
\text { อุดก้น } \\
\text { เรือรัง } \\
8\end{array}$ & $\begin{array}{l}\text { วัลโรคปอด } \\
\text { หรือวัลโรด } \\
\text { ส่วนอี่น }\end{array}$ & $\begin{array}{l}\text { อัมพาตครี่งัก โรด } \\
\text { หลลอดเเือดสมอง } \\
\text { (ตีบตัน แตก) }\end{array}$ \\
\hline 1 & 1 & 2 & 25 & 1 & 0 & 0 & 0 \\
\hline 2 & 2 & 5 & 52 & 2 & 0 & 0 & 2 \\
\hline 3 & 2 & 0 & 29 & 2 & 0 & 0 & 0 \\
\hline 4 & 1 & 4 & 48 & 2 & 0 & 1 & 2 \\
\hline 5 & 3 & 6 & 104 & 9 & 1 & 0 & 0 \\
\hline 6 & 2 & 4 & 21 & 1 & 0 & 0 & 0 \\
\hline 7 & 1 & 2 & 43 & 1 & 0 & 0 & 0 \\
\hline 8 & 0 & 3 & 23 & 4 & 0 & 0 & 2 \\
\hline 9 & 0 & 2 & 59 & 4 & 2 & 0 & 0 \\
\hline 10 & 1 & 7 & 18 & 0 & 0 & 0 & 0 \\
\hline 11 & 0 & 5 & 46 & 5 & 0 & 0 & 0 \\
\hline 12 & 0 & 0 & 7 & 0 & 0 & 0 & 0 \\
\hline ทึ้งหมด & 13 & 40 & 475 & 31 & 3 & 1 & 6 \\
\hline
\end{tabular}

Figure 2 Reports of the database system: (a) pie and stacked bar charts visualizes religious beliefs for each of 12 community (light blue means Buddhist, dark blue means Christian, and light green means Islam), and (b) 7 chronic diseases found six months prior in 12 communities (1. coronary disease, heart disease, and myocardial infarction; 2. other heart disease, heart attack, and heart valve disease; 3. hypertension; 4. asthma; 5. lung diseases, 6. tuberculosis; and 7. cerebrovascular disease). 
http://wjst.wu.ac.th

\section{Visualization and analytical tools}

The data visualization tools provided graphical analytic reports for each community. A visual and real-time representation of important aggregated data related to health information, including the health criteria, were presented on the dashboard. The visualization tools provided demographical and statistical reports for each community which summarized data determined to be essential for health promotion use. These tools were presented on the dashboard in real-time, with aggregated data related to population and elder health information, to automatically calculate health status and the elder's house position on Google Maps. The database system generated visual demographical reports in stacked bar and pie chart formats (Figure 2a). This tool was designed to present data in bar and pie chart and data table formats to allow surveillance, and to obtain epidemiology data from top ten statistical analyses of data on the prevalence of diseases faced in communities (Figure 2b). GIS data from the database system was used to visualize the distributed locations of the prevalence of diseases. Instead of presenting the raw data through tables or lists, we uploaded our presentation as a group of colorful balloons via Google maps (Figure 3). Streets, places, and images surrounding the selected location could also be viewed in these maps. Moreover, the health status of the elder could be viewed in detail by mouse clicking on the balloons.

\section{โรคที่พบ 10 อันดับแรก}

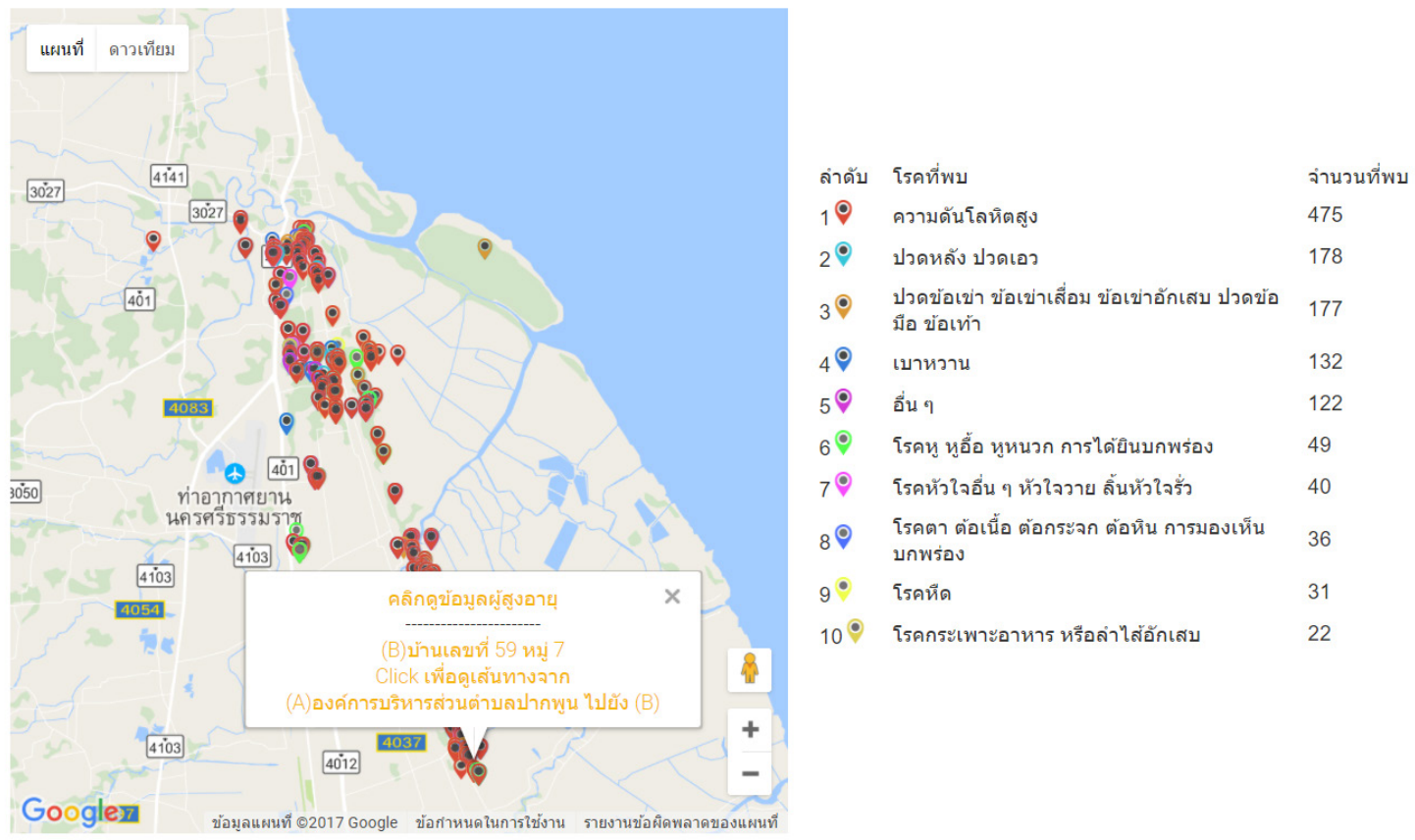

Figure 3 Distributed locations of the prevalence of the top ten diseases found in elders in the communities. These were: 1) hypertension, 2) back pain, 3) arthritis, 4) diabetes, 5) other, 6) ear problems, 7) other heart disease, heart attack, and heart valve disease, 8) eye disease, 9) asthma, and 10) gastrointestinal disease. 


\section{Evaluation of database system effectiveness and user perceptions}

The usability system evaluation results of the nursing team from Walailak University and those involved in the provision of elderly services in the community were as follows; the overall average user satisfaction with the database system was 3.84 and 3.82, respectively. In terms of average value for each main heading of the questionnaire, comprising four main headings, user ratings were highest in the system being able to support operation (4.05 and 4.04). The users also showed that they were concerned about clear transaction classification (3.65 and 3.63). Considering each main heading, in terms of the user-program interaction, users were satisfied that the database system was easy to access and run at an appropriate speed (3.75 and 3.74). For the database system's features, users were satisfied that the system could provide GIS reports for support in decision making (3.96 and 3.94). When asked about the performance and security, they were satisfied that the system had efficient and secure data storage, (3.86 and 3.84). Finally, in the service quality of the system, they reported that the overall efficiency of the system (4.05 and 4.04) was satisfactory. There was no different value found in user satisfaction with the database system between groups of users.

\section{Discussion}

This study developed a database health system for elder care based on the database life cycle, consisting of initial database study, database design, implementation and loading, testing and evaluation, operation, and maintenance and evaluation [23]. The findings showed that the database users were most satisfied with quality in service of the system, because it could help facilitate their work. Our results indicate that the elder database health system supported and helped the health care teams to manage care for elders in the community, because it helped health care teams work quickly on care and reduced their workload in searching and putting together all of the elders' data, and suggested that health promoting hospitals should update new data at least once a month [24]. Especially, it can support efficient elder care, manage an efficient service system and coordinate the health network for care, due to it containing information about the integrated data of health status and social status, using technologies supporting integrated-care delivery through better assessment, planning, organization, and monitoring [25], and with integrated information visualization which could potentially increase the understanding of community well-being status and ultimately enhance decision-making and strengthen communities [22]. Information pulling from the database developed success factors for elder care, because it was used for the intended work of a health network, with beneficial management, cooperative partners, and good leaders [26]. In addition, research on a database for care patients studied about internet referral database systems, with the results showing that the effects of development databases can help health care teams to refer patients and reduce the period of care [27]. Moreover, there was also a study about health-related knowledge after using an online medical database of elders; after the elders used the database, knowledge for elder care could be improved [28]. Based on this research, it was proposed that those who are responsible for elderly care in community, such as t health promotion hospitals and sub-district administration organizations, should develop and implement databases that are consistent with the contexts of their areas, in order to increase quality and efficiency of care, because it supports classified groups of the elderly and seeks appropriate care for them that supports continuum care. For example, the use of information to design health care improves patient participation in self-care [6], helps vulnerable frail elders receive more effective care [11], provides for electronic case recording wristbands warning of falls or accidents, helping health care teams to arrive at locations rapidly and help immediately [29] and home-based Mhealth (mobile health) systems to assist elderly outpatients to improve medication safety and prevent medication errors [30], and can be used as a screening tool to identify elderly populations at high risk for hospitals and emergency rooms [31]. Therefore, efficient health database systems can help health care teams to develop care for elders in the community. 
http://wjst.wu.ac.th

\section{Conclusions}

We have developed tools to support health care teams to care for elders in the Pak Poon community: 1) an elder assessment form for collecting data, and 2) a database system supporting the process of data entry and retrieval of information from the system that can be used to effectively plan the care of the elderly. It has been stated that the developed health database system can help facilitate better performance, because it helps in analyzing, interpreting, and reporting for quick decision-making. We developed and tested the database system until the health teams were satisfied. However, each community is different and has cultural diversity. Therefore, it is proposed that the health care teams in the community ought to develop database systems for the care of elders that are appropriate to their contexts.

\section{Acknowledgements}

We thank the staff from Pak Poon sub-district administration organization and Bansalabangpoo health promotion hospital for their collaboration with this project. Financial support was obtained from the Institute of Research and Innovation, Walailak University, Thailand.

\section{References}

[1] Population of Thailand in the future (in Thai), Available at: http://www.ipsr.mahidol.ac.th, accessed July 2014.

[2] The world's population and the population of Thailand, BE 2543 to 2568, Available at: http://service.nso.go.th, accessed August 2013.

[3] Foundation of Thai Gerontology Research and Development Institute (TGRI). Annual Report: The Elderly, Thailand 2010 (in Thai). Bangkok QPL, Bangkok, 2012.

[4] P Pramote. Elderly Situation, Trends and the Impact of the ASEAN Engagement of Thailand in Year 2015 (in Thai). Bangkok, 2012.

[5] P Hirdes. Addressing the health needs of frail elderly people: Ontario's experience with an integrated health information system. Age Ageing 2006; 35, 329-31.

[6] S Koch and M Hägglund. Health informatics and the delivery of care to older people. Maturitas 2009; 63, 195-9.

[7] M Kaye. Health literacy and informatics in the geriatric population: The challenges and opportunities. Online J. Nurs. Informat. 2009; 13, 1-19.

[8] S Koch. Healthy ageing supported by technology: A cross-disciplinary research challenge. Inform. Health. Soc. Ca. 2010; 35, 81-91.

[9] M Marschollek, K Wolf, R Haux, S Mix, B Effertz and E Steinhagen-Thiessen. ICT-based health information services for elderly people: Past experiences, current trends, and future strategies. Med. Inform. Internet. 2007; 32, 251-61.

[10] L Dumrikarnleard. Circumstances and Care Needs of the Elderly in the Community (in Thai). Bankok, 2012.

[11] SA Zwijsen, AR Niemeijer and CM Hertogh. Ethics of using assistive technology in the care for community-dwelling elderly people: An overview of the literature. Aging Ment. Health 2011; 15, 419-27.

[12] U Jaraeprapal and S Aekwarangkoon. Geographic information system development for community health promotion. Thai J. Nurse C. 2008; 23, 49-60.

[13] Bureau of Promotion and Protection of the Elderly of Thailand. Law Related to the Elderly and Local Government Organizations. The Office of Elderly Promotion and Protection, Bangkok, 2011.

[14] R Arellano, FE Balcázar, F Alvara and S Suárez. A participatory action research intervention in a rural community of Mexico concerns report method. Univ. Psychol. 2015; 15, 1197-208.

[15] S Kemmis and RM Taggart. Participatory Action Research. In: NK Denzin and YS Lincoln (Eds). The Sage Handbook of Qualitative Research. $3^{\text {rd }}$ ed. Sage, Thousand Oaks, 2005, p. 559-603.

[16] P Diviacco. An open source, web based, simple solution for seismic data dissemination and collaborative research. Comput. Geosci. 2005; 31, 599-605. 
http://wjst.wu.ac.th

[17]X Ma, Y Li, M Bourgeois, M Caffee, D Elmore, D Granger, M Paul and S Preston. Web CN: A webbased computation tool for in situ-produced cosmogenic nuclides. Nucl. Instrum. Meth. 2007; 259, 646-52.

[18] B Delipetrev, A Jonoski and DP Solomatine. Development of a web application for water resources based on open source software. Comput. Geosci. 2014; 62, 35-42.

[19] MS Hutton, S Azevedo, R Beeler, R Bettenhausen, E Bond, A Casey, J Liebman, A Marsh, T Pannell and A Warrick. Experiment archive, analysis, and visualisation at the National Ignition Facility. Fusion Eng. Des. 2012; 87, 2087-91.

[20] T Lotz, J Nieschulze, J Bendix, M Dobbermann and B König-Ries. Diverse or uniform? Intercomparison of two major German project databases for interdisciplinary collaborative functional biodiversity research. Ecol. Inform. 2012; 8, 10-9.

[21] J Soh, X Dong, SM Caffrey, G Voordouw and CW Sensen. Phoenix 2: A locally installable largescale 16S rRNA gene sequence analysis pipeline with Web interface. J. Biotechnol. 2013; 167, 393403.

[22] P Jinpon, M Jaroensutasinee and $\mathrm{K}$ Jaroensutasinee. Integrated information visualization to support decision-making in order to strengthen communities: Design and usability evaluation. Inform. Health Soc. Care 2017; 42, 335-48.

[23] P Rob and C Coronel. Database Systems: Design, Implementation \& Management, Seventh Edition 2007, Thomson Course Technology. Available at: http://www.pravinshetty.com/Db/wk2/SG/ FIT1004SG2.pdf, accessed July 2014.

[24] P Srisilapanan, D Lasuka, P Lerttrakarnnon, J Suwannaboot, K Yakhamjae, W Sriwichai and N Kanthasap. Development of Elder Health Information System: A Case Study of Lumphun Province. Health Information System Development Office, Thailand, 2010.

[25] N Dubuc, ND Colli, L Bonin, C Corbin, I Labrecque, J Guilbault, V Guillot, S Lessard and S Dubuc. Development of a computerized integrated-care-pathway system to support people-centred and integrated care: Usefulness of the participatory design method. Int. J. Interg. Care 2016; 16, 91.

[26] P Opasanant, P Pa-in and S Punyawong. Development of care system for dependent older persons in community. J. Nurs. Sci. Health 2015; 38, 137-46.

[27] T Thammakoon, K Kaewoun, N Raungsakun and N Suchart. Internet referral database system development, Phitsanulok province. Buddhachinaraj Med. J. 2009; 26, 16-28.

[28] O Freund, I Reychav, R McHaney, E Goland and J Azuri. The ability of older adults to use customized online medical databases to improve their health-related knowledge. Int. J. Med. Inform. 2017; 102, 1-11.

[29] J Piotrowicz, A Soll, U Kielar, A Zwiefka, A Guligowska, M Piglowska, T Kostka and D Kurpas. ICT and environmental support for patient with frailty syndrome: Carewell project, focus project, and sunfrail project. Med. Sci. Pulse 2017; 11, 37-43.

[30] M Tsenga and H Wub. A cloud medication safety support system using QR code and Web services for elderly outpatients. Tech. Health Care 2014; 22, 99-113.

[31] SJ Crane, EE Tung, GJ Hanson, S Cha, R Chaudhry and PY Takahashi. Use of an electronic administrative database to identify older community dwelling adults at high-risk for hospitalization or emergency department visits: The elders risk assessment index. BMC Health Serv. Res. 2010; 10, 338 . 